\title{
UMA HISTORIADORA ENTRE A FAMÍLIA, AS MULHERES E AS CRIANÇAS NO SÉCULO XIX: ENI DE MESQUITA SAMARA
}

\author{
Esmeralda Blanco B. de Moura \\ Universidade de São Paulo
}

Ao encerrar a introdução de As mulheres, o poder e a família. São Paulo, século $X I X$, Eni de Mesquita Samara deixou registrado à própria família, ao esposo Eduardo e aos filhos Dudu e Lívia, o agradecimento pela "relação intensa, misto de gratidão e de culpa". Define, então, a família, como seu "reduto primeiro", de quem entende haver roubado "muitos momentos de convivência" em virtude do trabalho, no caso, sua tese de doutorado".

A palavra culpa muitas vezes compareceu às conversas informais - senão às discussões - que compartilhávamos no Centro de Estudos de Demografia Histórica da América Latina-CEDHAL, nas demais instâncias de nossa Faculdade, em outros espaços próprios ao debate acadêmico, seminários, simpósios, congressos. Afinal, éramos ambas mulheres às voltas com a história das mulheres, portanto com nossa própria história, sempre prontas a trazer para o primeiro plano de nossas preocupações a condição feminina no tempo pretérito e em nosso próprio tempo, sempre prontas a refletir sobre nós mesmas, sobre nosso envolvimento com o trabalho e o sentimento de culpa que, fruto de uma dentre tantas outras construções culturais quanto às mulheres, por vezes nos divertia, não sem insistir em nos acompanhar. Sentimento, alimentado pela percepção de que fazíamos parte de uma geração de mulheres que, definitivamente, para se sentirem inteiras,

SAMARA, Eni de Mesquita. As mulheres, o poder e a familia. São Paulo, Século XIX. São Paulo: Marco Zero; Secretaria de Estado da Cultura de São Paulo, 1989, p. 14. 
completas, precisavam administrar o fato de que, contraditoriamente, deveriam ser mulheres divididas entre a casa e o trabalho.

Aos poucos, à medida que a pesquisa avançava, que nos tornávamos "íntimas" das mulheres que nos haviam precedido na história, devido, talvez à maturidade, talvez à percepção de que afinal tudo havia se encaminhado bem para nossas famílias e nosso trabalho, o sentimento de culpa passou a ser substituído pela sensação de que valera a pena dar a conhecer a história de nossas mulheres nos mais distintos momentos e espaços em que haviam transitado.

Creio que são necessárias algumas palavras sobre o quanto a história das mulheres e, com ela, a história da família, das crianças, os estudos de gênero, tornaram-se centrais nas tendências historiográficas inauguradas nos últimos vinte e cinco anos do século XX, justamente na confluência com a proclamação do ano de 1975 pela ONU como Ano Internacional da Mulher e da constância das comemorações, a partir desse momento, do Dia Internacional da Mulher. No ano seguinte, a afirmação de June Hahner soaria como estímulo e desafio: "A história da mulher no Brasil, tal como a das mulheres em vários outros países, ainda está por ser escrita". ${ }^{2}$

Nesse momento, dedicava-me à pesquisa sobre as mulheres e as crianças operárias nos primórdios da República ${ }^{3}$ e Eni Samara voltava-se para as Casas Grandes e para o "papel fundamental" da família na sociedade colonial. ${ }^{4}$ Sua escolha recaíra, assim como minha própria escolha, sobre a cidade de São Paulo, pois esse cenário the pareceu, no transcorrer do século XIX, "um campo fecundo de investigação, com uma sociedade complexa e em transformação". ${ }^{5}$

As conclusões a que chega são bem sistematizadas por Maria Stela Bresciani na contracapa de As mulheres, o poder e a família:

\footnotetext{
2 HAHNER, June E. A mulher no Brasil: textos coligidos e anotados por June E.Hahner. Tradução de Eduardo F. Alves. Rio de Janeiro: Civilização Brasileira, 1978, p. 9.

3 Vide MOURA, Esmeralda Blanco B. de. Mulheres e menores no trabalho industrial em São Paulo: os fatores sexo e idade na dinâmica do capital. Petrópolis: Vozes, 1982.

4 SAMARA, Eni de Mesquita, op.cit.

5 Idem, Ibidem, p. 16 e 10.
} 


\section{Esmeralda Blanco B. de MOURA. Uma historiadora entre a família, as mulheres e as crianças no séc. XIX.}

Famílias patriarcais e sua extensa rede de dependentes confirmam uma tendência herdada dos tempos coloniais, mas surpreendentemente não constituem a forma predominante de organização familiar. ${ }^{6}$

Na base dessa assertiva, a desconstrução, como aponta Bresciani, de "modelos rígidos consagrados pela literatura sobre a sociedade brasileira" e a preocupação de Samara com a possível variedade de estruturas familiares no tempo e no espaço, sem invalidar modelos como o de Gilberto Freyre ${ }^{8}$, mas trazendo à tona outra percepção: a de que não seria possível falar em um padrão único quanto à família paulista. Se o modelo patriarcal de família aplicava-se, por exemplo, aos detentores da riqueza e do poder, percebia-se, em São Paulo, nas várias freguesias - Penha, Nossa Senhora do Ó, Santa Efigênia, ao Sul e ao Norte da Sé - um universo de contrastes na estrutura familiar alinhado aos vários setores de atividade econômica; percebia-se, ainda, uma miríade de categorias de domicílio - singulares, desconexos, nucleares, extensos, aumentados, fraternos -, unidades familiares em que Samara foi buscar informações valiosas: quem as chefiava, se constituíam famílias legalizadas ou não, quais os fundamentos das relações que abrigavam, o parentesco, os vínculos estabelecidos pelo trabalho. Desse modo, confere visibilidade, também, às uniões ilícitas - para os padrões da religião e da legislação da época - formadas entre moradores locais à sombra do concubinato e à revelia da ideia de casamento.

No interior desse estudo sobressaem as mulheres, a função específica do casamento numa sociedade em que eram poucas as opções que lhes restavam, em que sua imagem estava associada aos papéis de esposa e mãe, mas em que Samara pôde perceber, como ressalta, "certo exagero dos estudiosos e romancistas ao estabelecerem o estereótipo do marido dominador e da mulher submissa". Paulatinamente, a análise a faz aportar no que denomina "área de influência feminina", pois se vê diante de uma documentação que lhe sugere "novas imagens da mulher na família e na sociedade, com uma participação mais ativa, embora o seu papel fosse limitado, face à manutenção dos privilégios masculinos". 9

Sua análise confere, portanto, outra dinâmica a esse contexto, pois, ao lado das mulheres que ficavam em casa e que, no interior das quatro paredes do lar,

${ }^{6}$ BRESCIANI, Maria Stela. Contracapa. In: SAMARA, Eni de Mesquita, op.cit.

7 Idem, Ibidem.

8 A referência de Samara à clássica obra de Gilberto Freyre Casa Grande e Senzala: formação da família brasileira sob o regime da economia patriarcal corresponde, no caso, à $9^{a}$ edição em 2 volumes publicada no Rio de Janeiro, em 1977 , pela editora José Olympio.

9 SAMARA, Eni de Mesquita, op.cit., p. 105, 110 e 106. 
talvez fossem submissas - revela mulheres empenhadas na defesa dos próprios direitos no âmbito da sociedade conjugal, assim como revela, sobretudo nas camadas mais empobrecidas da população, mulheres absorvidas pelo trabalho, na chefia dos próprios domicílios, a gerir o orçamento doméstico, a cuidar dos filhos ilegítimos.

Impossível dar conta da densidade dessa análise que a coloca em contato com homens e mulheres, casados, solteiros, vivendo em concubinato, unidos em casamento legítimo, dispostos a desfazer os laços conjugais, às voltas com a partilha de bens; que a coloca em contato com brancos, negros, mestiços, com a população livre e também cativa, que a coloca em contato com as crianças. Em relação aos pequenos, mostra-se sensibilizada quanto à alta mortalidade infantil, recorrente ao longo da história brasileira, não só na sociedade paulista, a abranger crianças de todas as condições econômicas, legítimas e ilegítimas, escravas ou não, crianças de todas as idades, nem sempre na primeira infância:

Os números são realmente surpreendentes e a morte tão frequente parece ter sido encarada como um acontecimento quase natural. (...) Sob esse aspecto, a religião era o consolo dos pais, ajudando na compreensão dessa fatalidade que atingia os filhos de ricos e de pobres. ${ }^{10}$

Muito poderia ser dito, ainda, no que tange a essa análise, mas nada melhor para introduzir a menção à colaboração de Eni Samara aos estudos de gênero, do que a frase com que encerra As mulheres, o poder e a família:

Os processos de divórcio revelam uma nova dimensão das relações do casal. As queixas das esposas quanto às sevícias e ao adultério e as próprias aspirações face ao casamento e à vida conjugal divergiam do estereótipo de submissão e reclusão. ${ }^{11}$

A historiadora ampliara consideravelmente a visibilidade social da mulher e, no passo seguinte, aportaria nos estudos de gênero, dimensão latente na obra a que fiz referência até o momento, insinuada no âmbito da historicidade das relações entre homens e mulheres.

O relacional de gênero tornar-se-ia "tema preferencial de expressiva produção historiográfica", palavras da historiadora Ismênia de Lima Martins na apresentação da obra Gênero em debate: trajetória e perspectivas na historiografia contemporânea, que Samara escreve em parceria com Raquel Soihet e

\footnotetext{
${ }^{10}$ Idem, Ibidem, p. 50.

${ }^{11}$ Idem, Ibidem, p. 174.
} 
Maria Izilda S. de Matos. ${ }^{12}$ Parte considerável da obra de Samara insere-se nessa produção historiográfica, cujo fundamento ultrapassa as diferenças biológicas entre homens e mulheres, para apreender a subjetividade inerente às construções culturais quanto ao feminino e ao masculino.

Nos estudos de gênero, a historiadora não se manteve restrita à situação das mulheres brasileiras, mas ampliou esse escopo, com fins comparativos, à trajetória das mulheres latino-americanas, atenta à pluralidade, do que resultou a organização da obra As idéias e os números do gênero: Argentina, Brasil e Chile no século $X I X .{ }^{13}$ Contudo, melhor do que resumir sua perspectiva de análise é remeter às suas próprias palavras na Apresentação de $O$ discurso e a construção da identidade de gênero na América Latina, título do capítulo que integra a obra anteriormente citada, Gênero em debate:

Pensar em Gênero e Identidade conjuntamente significa discutir um tema [complexo, bem como, elaborar] as relações entre os sexos, na sua perspectiva cultural, e os seus significados especificos para a América Latina, o que, em sintese, pressupõe uma reflexão sobre a "diferença", nas práticas cotidianas, na elaboração do discurso, no processo de socialização e na construção da identidade social de gênero. ${ }^{14}$

Reflexão que, no entendimento da autora, deve articular gênero a variáveis, tais como etnia e classe social, e ser capaz, também, de demonstrar sensibilidade para apreender e compreender as semelhanças.

Ao incorporar os estudos de gênero a sua investigação, a historiadora desenvolve uma análise com fundamento na discussão teórica da relação gênero e trabalho, dimensão que, com base nos dados demográficos sobre a população brasileira, explora comparativamente quanto a São Paulo, Minas Gerais, Bahia e Ceará, regiões distintas entre si em termos econômicos, alicerçadas, respectivamente, na exportação do café, na lavoura de subsistência destinada a abastecer as cidades, na produção de gêneros tropicais - algodão, cacau, tabaco - para o mercado externo. Preocupada em desvendar questões atinentes à mão-de-obra feminina, oportunidades e mercado de trabalho no Brasil do século XIX, volta-se para sua presença no quadro de transição para o assalariamento, convicta de que

${ }^{12}$ MARTINS, Ismênia de Lima Martins. Apresentação. In: MATOS, Maria Izilda S. de; SOLER, Maria Angélica (Orgs.). Gênero em debate: trajetória e perspectivas na historiografia contemporânea. São Paulo: EDUC, 1997, p. 7.

${ }^{13}$ SAMARA, Eni de Mesquita (Org.). As idéias e os números do gênero: Argentina, Brasil e Chile no século XIX. São Paulo: Hucitec; CEDHAL; FFLCH-USP; Fundação VITAE, 1997.

${ }^{14}$ SAMARA, Eni de Mesquita. O discurso e a construção da identidade de gênero na América Latina. In: MATOS, Maria Izilda S. de; SOLER, Maria Angélica (Orgs.), op.cit., p. 13. 
"o destino de muitas mulheres no Brasil, contrariando um modelo de ociosidade descrito pela historiografia" se cumprira às voltas com a necessidade de "prover o próprio sustento e o de sua família". ${ }^{15}$

Resta pontuar o quanto o conjunto de sua obra está fundamentado em inegável diversidade de fontes, manuscritas ou não, na leitura atenta da historiografia e em discussão teórica sempre criteriosa e atualizada que, em seus estudos, cumpre seu verdadeiro papel, o de unificar a análise, o de lhe imprimir coerência.

Eni de Mesquita Samara e eu fomos colegas de Graduação, de Pós-Graduação e como docentes no Departamento de História da Faculdade de Filosofia, Letras e Ciências Humanas da Universidade de São Paulo. Compartilhamos encontros acadêmicos no Brasil e no exterior, bancas de Mestrado e de Doutorado, cursos no Museu Paulista da mesma Universidade durante sua gestão, a organização de eventos acadêmicos e cursos no CEDHAL, assim como a direção deste centro de estudos, a edição da Revista População e Família, coletâneas de artigos. Além disso, compartilhamos a pesquisa em História da Família, das Mulheres, das Crianças e em História de São Paulo. A proximidade profissional, mas acima de tudo a afinidade temática, o olhar constantemente voltado para a mulher entre a casa e o trabalho, entre os cuidados com as crianças e o desempenho nas atividades produtivas, transformou-se em amizade.

Para finalizar, devo pontuar que compartilhávamos, também, o entusiasmo quando nos víamos diante de novas possibilidades e perspectivas de análise e muitas convicções. Dentre elas, a de que fazer História da Família, das Mulheres, das Crianças, voltar-se para os estudos de gênero, não é fazer uma história de menor significado. Essa foi uma das lutas que empreendemos juntas, sentido em que o CEDHAL foi nossa trincheira, convictas de que toda essa história não é uma história vã, mas uma história que foi gestada em meio às tensões de nosso próprio tempo, indicativas, no último quartel do século $\mathrm{XX}$, de que era hora de trazer, para o primeiro plano, temas e sujeitos históricos até então praticamente ausentes do debate historiográfico. ${ }^{16}$ Pode-se dizer portanto, que toda essa história nasceu de um compromisso e como tal se mantém.

\footnotetext{
${ }^{15}$ SAMARA, Eni de Mesquita (Org.). As idéias e os números do gênero: Argentina, Brasil e Chile no século XIX, op.cit., 1997, p. 26.

${ }^{16}$ Vide MOURA, Esmeralda Blanco B. de. Por que as crianças?. In: MOURA, Esmeralda Blanco B. de; CARVALHO, Carlos Henrique de; ARAÚJO, José Carlos Souza (Org.). A infância na modernidade: entre a educação e o trabalho. Uberlândia: EDUFU, 2007.
} 